\title{
Differential Regulation of the Release of the Same Peptide Transmitters from Individual Identified Motor Neurons in Culture
}

\author{
Matthew D. Whim and Philip E. Lloyd \\ Department of Pharmacological and Physiological Sciences and Committee on Neurobiology, University of Chicago, \\ Chicago, llinois 60637
}

\begin{abstract}
Aplysia motor neurons $\mathrm{B} 1, \mathrm{B2}$, and $\mathrm{B} 15$ synthesize the small cardioactive peptides $A$ and $B$ (SCPs). In previous studies using semi-intact preparations we have demonstrated that the SCPs are released from B15. Significant peptide release only occurred when B15 was stimulated at a high frequency or at lower frequencies with a long burst duration. In the behaving animal $B 15$ fires in patterns expected to release the SCPs. In contrast, in the behaving animal, neurons B1 and B2 fire at much lower frequencies. We therefore examined whether similar aspects of the stimulation pattern governed the release of the SCPs from B1 and B2. To monitor peptide release, all three neurons were individually cultured and newly synthesized peptides labeled with ${ }^{35} \mathrm{~S}$-methionine. Release of labeled SCPs was detected by HPLC of extracts of superfusates. By keeping spike number constant and varying the stimulation pattern, the release of the SCPs from $B 1$ and $B 2$ was found to be pattern insensitive. That is, regardless of the stimulation paradigm, each action potential released a similar amount of peptide. By severing the primary neurite, peptide release was found to occur mainly from the regenerated neurites and most likely from the intensely immunoreactive varicosities. Calcium- and stimulation-dependent release of the SCPs and a third neuropeptide termed buccalin A from motor neuron B15 was also observed in culture. The release of these peptides from B15 was found to be pattern sensitive as was observed in the semi-intact preparations. That is, the same number of spikes were more effective in evoking release of peptide when they were delivered in high-frequency bursts than when delivered at a tonic frequency. Thus, the parameters governing the release of a particular peptide can be retained by neurons in culture in the absence of their target tissues. Furthermore the release of the same peptide from different neurons can be independent of, or dependent on, the pattern of stimulation.

[Key words: transmitter release, motor neurons, Aplysia, SCPs, peptides, cultured cells]
\end{abstract}

While it is generally accepted that many neurons contain both conventional and peptide transmitters, the mechanisms controlling the relative release of the different transmitter types are

\footnotetext{
Received July 13, 1993; revised Nov. 24, 1993; accepted Jan. 13, 1994.

We thank P. I. Church for critical reading the manuscript. This work was supported by NSF IBN-9121146 and by Brain Research Foundation grants.

Correspondence should be addressed to Dr. Philip E. Lloyd, Department of Pharmacological and Physiological Sciences, University of Chicago, 947 East 58 Street, Chicago, IL 60637 .

Copyright (c) 1994 Society for Neuroscience $0270-6474 / 94 / 144244-08 \$ 05.00 / 0$
}

poorly understood. One important factor, however, appears to be the pattern of spike activity. Although use-dependent modulation has largely been studied with regard to fast-acting (conventional) transmitters, the release of peptides can also demonstrate an extreme case of nonlinearity. Activity-dependent release of peptides has been observed in a variety of systems including the vertebrate neurohypophysis (Dutton and Dyball, 1979; Cazalis et al., 1985; Bondy et al., 1987), cultured myenteric plexus neurons (Willard, 1990), and frog sympathetic ganglia (Peng and Horn, 1991). These and other studies have led to the general formulation that the release of peptide transmitters requires high-frequency firing (Bartfai et al., 1988). Although examples do exist where release has been observed with low firing frequencies (Lloyd et al., 1986), it is rare that peptide release can be demonstrated with single action potentials. This is in contrast to the release of conventional transmitters. Finally, in some cases it has been shown that peptide rcleasc can be sensitive to the pattern of stimulation (Cazalis et al., 1985; Whim and Lloyd, 1989).

To examine how the stimulation parameters control peptide release, we have previously used a neuromuscular preparation from the buccal mass of Aplysia. Central buccal motor neurons and the buccal muscles they innervate produce biting and swallowing movements during feeding. The release of the small cardioactive peptides (SCPs) was described from the cholinergic motor neuron B15. The SCPs comprise $\mathrm{SCP}_{\mathrm{A}}(11$ amino acids; Lloyd et al., 1987) and $\mathrm{SCP}_{\mathrm{B}}(9$ amino acids; Morris et al., 1982). The peptides have similar sequences and are processed from a single precursor (Mahon et al., 1985). Using two independent techniques it was demonstrated that the SCPs could be released from the terminals of B15 in the 15 muscle and that the release was sensitive to the stimulation pattern. Indeed, significant release of the SCPs only occurred when B15 was stimulated at a relatively high frequency with a long burst duration (Whim and Lloyd, 1990). Recordings made in the intact animal have indicated that B15 fires at up to $12 \mathrm{~Hz}$ for about $4 \mathrm{sec}$ with an interburst interval of about $3 \mathrm{sec}$ during various cycles of the feeding behavior (Cropper et al., 1990a,b). Hence, stimulation paradigms that result in release of the SCPs in isolated neuromuscular preparations occur in the behaving animal (Cropper et al., 1990a,b; Whim and Lloyd, 1990). The released SCPs have functional consequences in that they produce an increase in the amplitude and relaxation rate of muscle contractions in a manner similar to the application of exogenous SCPs. This type of modulation, which is widespread in the buccal motor system, may be partly responsible for the increase in amplitude of biting that occurs at the onset of feeding (Susswein et al., 1978; Church et al., 1993; Whim et al., 1993). 
Some information is also available about the release of the SCPs from other neurons termed B1 and B2, which are buccal motor neurons that innervate muscles of the gut. Recordings made in the behaving animal indicate that B1 and B2 fire at frequencies up to about $3 \mathrm{~Hz}$ for up to $1 \mathrm{sec}$ during ingestion of food (Lloyd et al., 1988). Stimulation-and calcium-dependent release of the SCPS from cultured B1 and B2 cells has been demonstrated using similar stimulation paradigms (Lloyd et al., 1986; Whim and Lloyd, 1992). It is clear that these three neurons (B1, B2, and B15), which contain the SCPs and release them in a stimulation-dependent manner, have very different physiological firing rates. These differences are largely intrinsic to the neurons since synaptically isolated $B 1$ and $B 2$ neurons can be made to fire no faster than $6 \mathrm{~Hz}$, while B15 can be driven at up to $50 \mathrm{~Hz}$ (Whim and Lloyd, 1989; unpublished observations). This raises the question of whether the release of the SCPs from $\mathrm{B} 1$ and $\mathrm{B} 2$ is regulated differently from the release of the same peptides from $\mathrm{B} 15$. In all three neurons, immunogold labeling indicates that the SCPs are localized to large dense-core vesicles in both somata and varicosities (Cropper et al., 1987; Reed et al., 1988).

To examine this question, we measured peptide release from individual isolated B1, B2, and B1 5 cells in culture by labeling newly synthesized peptides with ${ }^{35} \mathrm{~S}$-methionine. Using intracellular stimulation and a combination of HPLC and liquid scintillation counting, labeled peptides can be shown to be released in a stimulus- and $\mathrm{Ca}^{2+}$-dependent manner (Lloyd et al., 1986; Hall and Lloyd, 1991; Whim and Lloyd, 1992). This technique has two principal advantages. First, due to absence of postsynaptic cells the observed effects are, by definition, presynaptic. Second, the release of several peptides can be measured simultaneously. This is important because B 15 also synthesizes members of the buccalin family of peptides in addition to the SCPs (Cropper et al., 1987, 1988). One of the buccalins (buccalin A) contains a methionine residue and should also be labeled.

Using this experimental approach we demonstrate that the SCPs are released from B15 using stimulation paradigms that were similar to the activity recorded from freely behaving animals. By keeping spike number constant and varying the spike pattern, we observed that the release of the SCPs was sensitive to the pattern of stimulation. In contrast, although we could evoke the release of the SCPs from B1 and B2 using physiological stimulation paradigms we found that this release was essentially independent of pattern or frequency, each spike releasing a similar amount of peptide regardless of the stimulation parameters.

\section{Materials and Methods}

Most of the procedures have been described in detail previously (Whim and Lloyd, 1992) and are summarized briefly here. In the present experiments no difference between the release characteristics of neurons $\mathrm{B} 1$ and B2 were observed, and thus for simplification we will refer to these cells collectively as B1,2.

Cell culture. Buccal ganglia from Aplysia californica (50-100 gm) were desheathed and incubated in a $1 \%$ protease solution (Sigma type IX) in sterile normal artificial seawater (snASW) at $34^{\circ} \mathrm{C}$ for $\sim 2 \mathrm{hr}$. Buccal ganglion cells B1,2 and B15 were removed and plated individually in $1.5 \mathrm{ml}$ wells in $500 \mu \mathrm{l}$ culture medium $(50 \%$ snASW: $50 \%$ Aplysia hemolymph, containing penicillin-streptomycin-fungizone (GIBCO) to a final concentration of $1 \%$ ). Bl,2 are the largest cells on the caudal surface of the ganglia (Gardner, 1971), and are readily identifiable by visual criteria alone. Neuron B 15 is located on the rostral surface, typically at the lateral margin of the ventral motor neuron cluster (Cohen et al., 1978). With practice B 15 could usually be identified by visual criteria alone but in some experiments it was unambiguously located using electrophysiological criteria prior to incubation of the ganglion in pro- tease. Following $36 \mathrm{hr}$ in culture, newly synthesized peptides were labeled by the addition of ${ }^{35} \mathrm{~S}$-methionine for $24 \mathrm{hr}(0.25 \mathrm{mCi} / \mathrm{ml}$ for B 1,2 and $0.5 \mathrm{mCi} / \mathrm{ml}$ for the $\mathrm{B} 15$ neurons; see below) and then washed with a high $\mathrm{Mg}^{2+}(110 \mathrm{~mm})$, low $\mathrm{Ca}^{2+}(2 \mathrm{mM})$ (approximately twice normal $\mathrm{Mg}^{2+}$ and 0.2 times normal $\mathrm{Ca}^{2+}$ concentrations) ASW for 2-6 hr.

Release of radiolabeled peptides. Cells were impaled with two lowresistance microelectrodes, one to inject current, the other to monitor membrane potential. The culture well was superfused with snASW at a rate of $0.5 \mathrm{ml} \mathrm{min} \mathrm{m}^{-1}$ (about 1 bath volume per minute). Typically cells were spontaneously active $(\sim 1 \mathrm{~Hz}$ for $\mathrm{Bl}, 2$ and $\sim 5 \mathrm{~Hz}$ for B15) and were hyperpolarized to just below threshold. The superfusate contained bovine serum albumin $(14 \mu \mathrm{g} / \mathrm{ml})$, an effective carrier protein for the SCPs (Whim and Lloyd, 1992). Most experiments consisted of nine sequential periods each lasting $15 \mathrm{~min}$. Collection periods $1,3,4,6,7$, and 9 were washes. In periods 2,5 , and 8 the cell was stimulated to fire spikes in a variety of patterns for $5 \mathrm{~min}$ followed by a $10 \mathrm{~min}$ period of silence (B15) or 2 min followed by a 13 min period of silence $(B 1,2)$. Individual spikes were driven with brief depolarizing pulses $(15 \mathrm{msec}$ for B15 and $40 \mathrm{msec}$ for the larger B1,2). Spikes faithfully followed pulses throughout the experiments. Longer stimulation periods and a higher specific activity of ${ }^{35} \mathrm{~S}$-methionine were used for experiments using B 15 because it contains lower levels of the SCPs than B1,2 (Lloyd et al., 1987). Superfusate from each collection period was collected on ice, acidified with trifluoroacetic acid (TFA; final concentration, $10 \mathrm{~mm}$ ) and spiked with $2 \mathrm{nmol}$ each of a variety of unlabeled peptides. For the B1,2 experiments we used the SCPs since these appear to be the only methionine-containing peptides released from the cells in culture (Lloyd et al., 1986). Since we did not know which peptides would be released from cultured B15 neurons, the collected superfusate was spiked with several peptides known to be present in the buccal ganglia (SCPs, buccalin A, myomodulin A, and FMRFamide). The superfusate was then immediately passed through a $\mathrm{C}_{18}$ Sep-pak cartridge (Waters). Retained material was eluted with $2 \mathrm{ml}$ of $90 \% \mathrm{CH}_{3} \mathrm{CN}$ containing $10 \mathrm{~mm}$ TFA, lyophilized, and run on HPLC using a $\mathrm{CH}_{3} \mathrm{CN}$ gradient with either TFA (B1,2 neurons; Hall and Lloyd, 1991) or HFBA as a counterion (B15 neurons; Church and Lloyd, 1991). Fractions coeluting with unlabeled synthetic peptides were collected and counted in a liquid scintillation counter. In some experiments with B15, several radioactive fractions were reanalyzed using a second mode of HPLC. Aliquots from the peaks of interest were pooled from several experiments, dried, and run on a linear $\mathrm{CH}_{3} \mathrm{CN}$ gradient with TFA as a counterion (Church and Lloyd, 1991).

In some B 1,2 experiments the release of the SCPs was measured before and after severing the neuritic projections from the soma. This was accomplished by removing the intracellular electrodes and transecting the primary neurite using a fine glass probe, and then reimpaling the soma. During this period the culture well was superfused with the high$\mathrm{Mg}^{2+}$ low-Ca ${ }^{2+} \mathrm{ASW}$ to reduce spontaneous transmitter release. Control experiments employed the same procedures except the neurites were not severed prior to reimpalement. For the purposes of statistical analysis, stimulation paradigms were compared using a two-tailed $t$ test, with a minimal level of significance of $P=0.05$. Experiments were only accepted if the cells remained healthy throughout (as judged by rest potential and spike amplitude).

Immunocytology. This was performed using procedures previously described for cultured neurons (Hall and Lloyd, 1991) except that the cells were incubated in a monoclonal antibody to $\mathrm{SCP}_{\mathrm{B}}$ (Masinovsky et al., 1988) diluted 1:50, followed by incubation in secondary antiserum, goat anti-mouse conjugated to fluorescein isothiocyanate (Tago) diluted $1: 200$.

\section{Results}

Effect of spike frequency on the release of labeled SCPS from $B 1,2$

Individual B1,2 cells which had been previously labeled with ${ }^{35} \mathrm{~S}$-methionine, were stimulated via intracellular electrodes to tonically fire at 1,3 , or $5 \mathrm{H} z$ for 2 min in three sequential stimulation periods. Each stimulation period was bracketed with control periods during which the neurons were hyperpolarized. The collected superfusate from each period was run on HPLC and the fractions corresponding to synthetic SCPs were counted. Between 1 and $5 \mathrm{~Hz}$ the release of the labeled SCPs was linear 
A

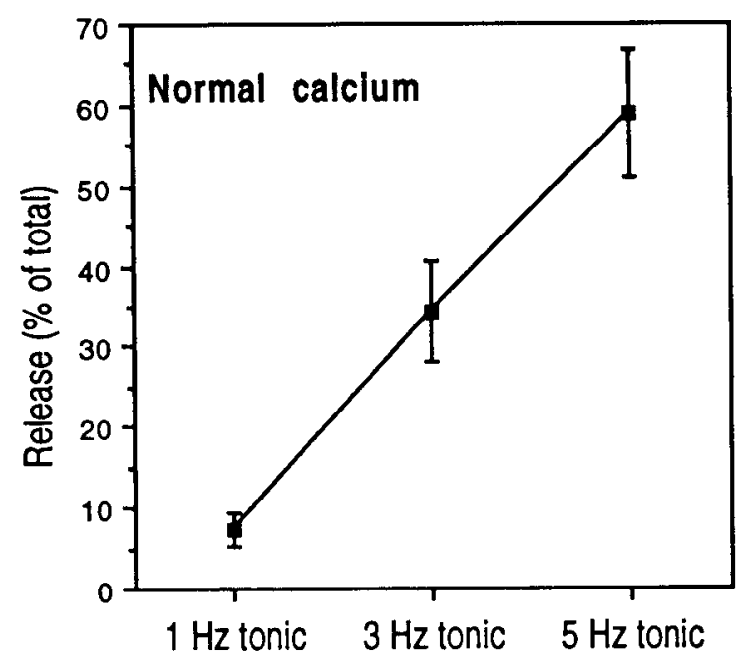

B

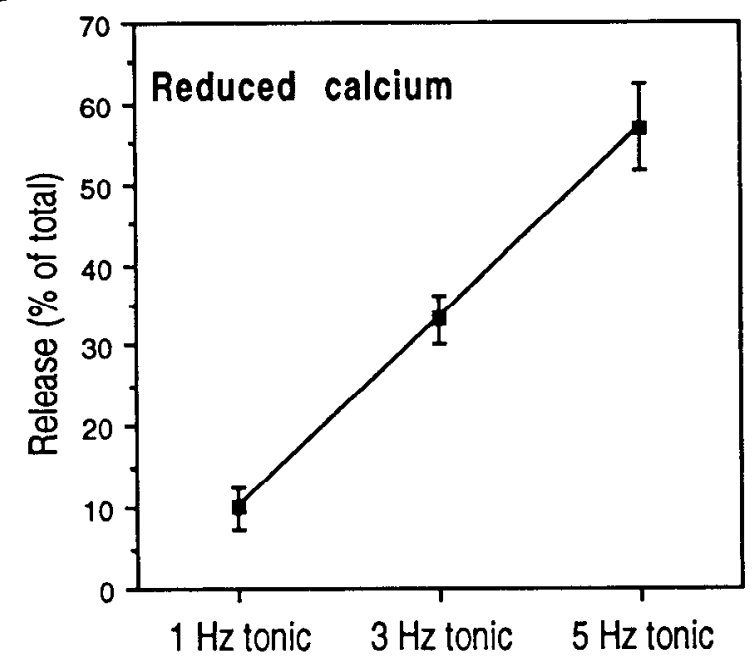

Figure 1. Effect of spike frequency on the release of labeled SCPs from cultured B1,2 neurons. Neurons were stimulated at the indicated tonic frequency for $2 \mathrm{~min}$ followed by a $13 \mathrm{~min}$ period of silence, and hyperpolarized during the control collection periods (see Materials and Methods). Each neuron was stimulated at 1,3 , and $5 \mathrm{~Hz}$ in an order that was systematically varied. Release of the SCPs was determined using HPLC and liquid scintillation counting. The stimulation-dependent release of peptide was determined as the amount of radioactivity in the SCP fractions in the release period minus the mean of the corresponding fractions in the pre- and poststimulation wash periods. Release was then expressed as percentage of total counts that eluted with the SCPs from the three collection periods. $A$, Release of labeled SCPS from $B 1,2$ was linearly dependent on spike frequency in snASW. Values are mean $\pm \mathrm{SD}(n=5) . B$, Release of labeled SCPs from $\mathrm{Bl}, 2$ was also linearly dependent on spike frequency when $\mathrm{Ca}^{2+}$ was reduced to $50 \%$ of normal levels $(5.5 \mathrm{~mm})$. Different neurons from $A$. Values are mean $\pm \mathrm{SD}(n=5)$.

(Fig. 1A). Thus, the total release was dependent only on the number of spikes, and not their frequency. This linear dependence on spike number is not due to the depletion of a readily releasable pool of peptide because the order in which the cells were stimulated at each frequency was varied.

In other systems it has been suggested that the pattern dependence of peptide release results from the availability of calcium (Peng and Horn, 1991). As an augmentation of transmitter release at the squid giant synapse can be uncovered in low calcium solutions (Swandulla et al., 1991) we reasoned that it might be possible to alter the linear relationship between spike number and peptide release by reducing external calcium levels. However, a reduction in external calcium levels by $50 \%$ did not alter the linear relationship between spike frequency and the release of labeled SCPS (Fig. $1 B$ ). Further reduction of calcium levels precluded monitoring relcase at the lower stimulation frequencies.

\section{Effect of spike pattern on the release of labeled $S C P_{S}$ from $B 1,2$}

Recordings made in the behaving animal indicate that $B 1,2$ fire in bursts at frequencics up to $3 \mathrm{~Hz}$ for up to $1 \mathrm{sec}$, although the pattern was variable (Lloyd et al., 1988). We therefore examined the release of the SCPS using more physiological patterns of stimulation than the tonic firing described above. Within each experiment the spike number was kept constant and the spike pattern was varied. We initially compared firing B 1,2 with three spikes in $0.5 \mathrm{sec}$ with an interburst interval of $0.5 \mathrm{sec}$, to firing tonically at $3 \mathrm{~Hz}$. (Fig. 2A). A small decrease in release was observed with the tonic firing paradigm but this was not significant $(t=0.77$, NS). We also compared firing B1,2 with three spikes in $0.5 \mathrm{sec}$ with the interburst interval lengthened to 2.5 sec, to a tonic firing frequency of $1 \mathrm{~Hz}$. (Fig. $2 B$ ). Again a small decrease in release of the SCPS was observed with the tonic firing paradigm although in this case, the effect was significant $(t=2.8, P<0.05)$. However, this effect was very small, particularly when compared to the pattern sensitivity of the release of peptides from B15 (see later).

\section{Somatic versus neuritic release of labeled SCPS from B1,2}

In some cultured neurons, release of transmitters can be observed from sites that are likely to be located at the somata (Haydon, 1988). Since it is possiblc that release from somata might be regulated differently than release from varicosities, we examined whether the pattern insensitivity of peptide release from B 1,2 could result from a non-neuritic site of release. To examine this question we compared the release of labeled SCPs from neurons before and after mechanically severing the neuritic processes from the cell body. In these experiments cells with monopolar morphology were used since this facilitated the severing of the neurites. Removal of most of the neuritic projection was found to result in the effective climination of the stimulation-dependent release of the SCPs (Fig. 3A). This was not due to the depletion of the releasable pool of peptide because in control experiments the amount of labeled SCPS in the second stimulation period did not decline (Fig. $3 B$ ). Although we did not stimulate the severed neurites to test whether they retained the ability to release peptide, it is unlikely that the loss of stimulation-dependent peptide release was as a result of cell trauma. First, after transection the somatic membrane potential stabilized to within $5 \mathrm{mV}$ of its original value and cells continued to fire overshooting action potentials. Second, leakage of peptide resulting from damage to the neurites did not occur since the background release of labeled SCPs did not increase following transection. Immunocytology of cultured $\mathrm{B} 1,2$ neurons revealed that nearly all the SCP-like immunoreactivity in the neurites was confined to varicosities (Fig. 4). We conclude that release of the SCPs is very likely occurring from these varicosities, and that although the soma contains labeled peptides (Lloyd et al., 1986) it is not competent to release them. 
A

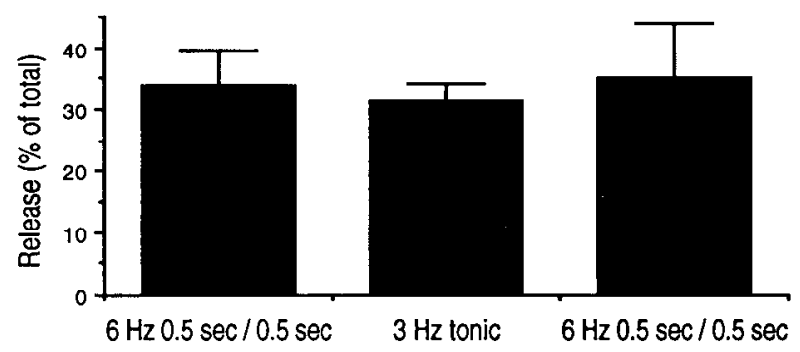

B

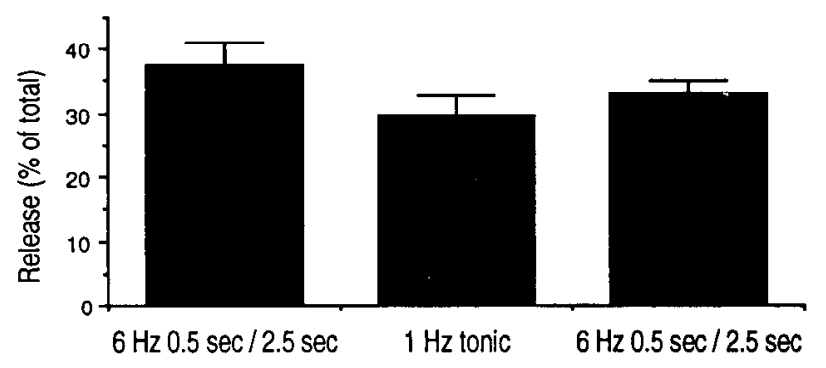

Figure 2. Effect of spike pattern on release of labeled SCPs from B1,2. Release of peptide was compared using stimulation paradigms that contained the same number of spikes but in which spike pattern was varied. $A$, Stimulation of $\mathrm{B} 1,2$ with three spikes in $0.5 \mathrm{sec}$ with $0.5 \mathrm{sec}$ interburst intervals (an instantaneous frequency of $6 \mathrm{~Hz}$ in the burst) released similar amounts of labeled SCPs as tonic stimulation at $3 \mathrm{~Hz}$. Values are mean $\pm \mathrm{SD}(n=6) . B$, Stimulation of $\mathrm{B} 1,2$ with three spikes in 0.5 sec with $2.5 \mathrm{sec}$ interburst intervals (an instantaneous frequency of 6 $\mathrm{Hz}$ in the hurst) released similar amounts of labeled SCPS as tonic stimulation at $1 \mathrm{~Hz}$. Values are mean $\pm \mathrm{SD}(n=4)$.

\section{Release of labeled peptides from $B 15$ is dependent on stimulation and external calcium}

Using a stimulation paradigm at the top end of the firing patterns observed in the behaving animal $(12 \mathrm{~Hz}$ for $4 \mathrm{sec}$ with $3 \mathrm{sec}$ interburst intervals), we determined which labeled peptides were released from individually cultured B 15 neurons. Each experiment consisted of three 15 min collection periods. Neurons were held hyperpolarized between stimulation periods. In the first collection period the culture well was superfused with a high $\mathrm{Mg}^{2+}(110 \mathrm{~mm})$, low $\mathrm{Ca}^{2+}(0.5 \mathrm{~mm}) \mathrm{ASW}$ and the neuron was stimulated for $5 \mathrm{~min}$ and then hyperpolarized for $10 \mathrm{~min}$. The superfusate was then changed to snASW. After 15 min equilibration, B15 was hyperpolarized throughout the second collection period. In the third period the well was superfused with snASW and the neuron was stimulated as in the first collection period. When B15 was stimulated in snASW there was a large increase in the number of counts that coeluted with the SCPS and buccalin A on HPLC. Smaller increases in counts were also observed for peaks that coeluted with myomodulin $\mathrm{A}$ and FMRFamide. To determine whether these radioactive peaks represented the authentic peptides, aliquots of each peak were reanalyzed using a second mode of HPLC with TFA as a counterion (Church and Lloyd, 1991). The appropriatc labcled pcaks continued to coelute with $\mathrm{SCP}_{\mathrm{A}}, \mathrm{SCP}_{\mathrm{B}}$, and buccalin A indicating that they represented the authentic peptides. However, the other two peaks did not coelute with myomodulin A and FMRFamide. The identities of these minor peaks were not further investigated and it is possible that they were breakdown products of the SCPs or buccalin A. After compensating for the difference
A
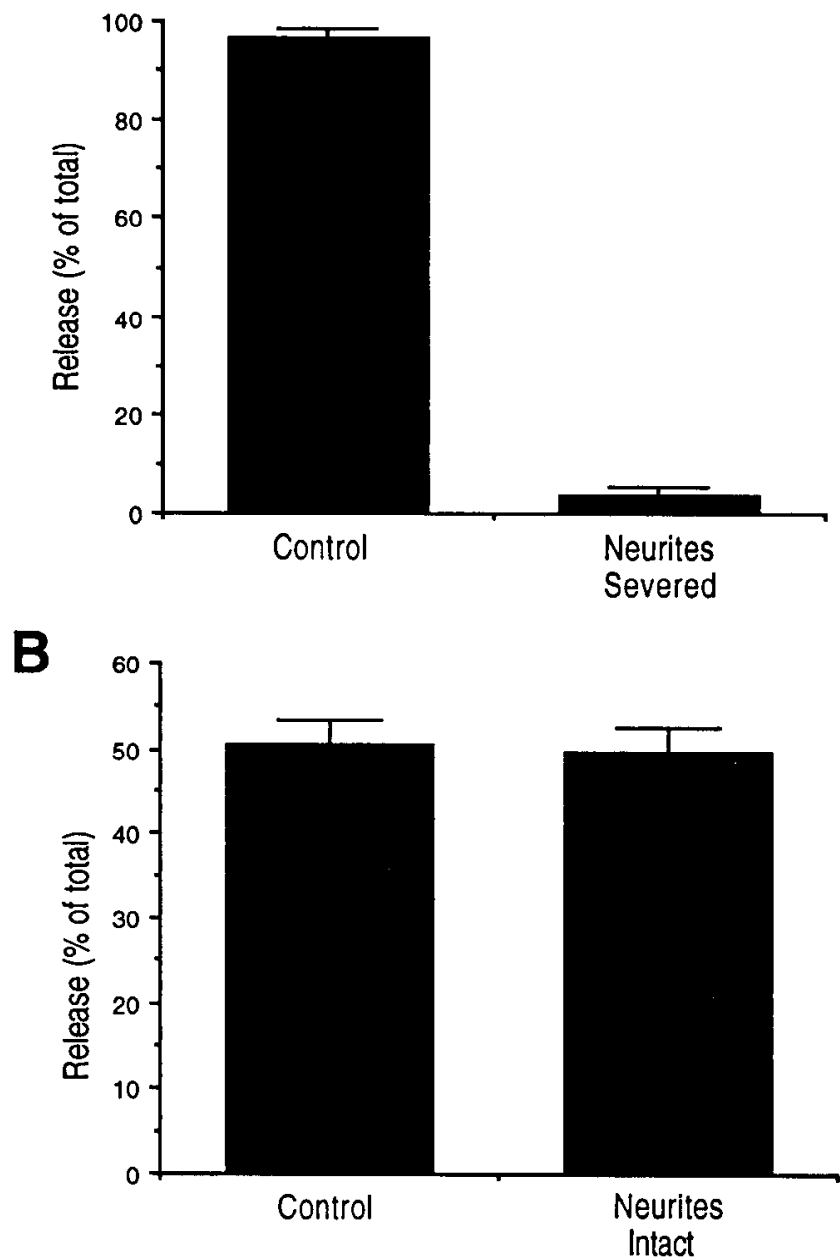

Figure 3. Release of labeled SCPs from B1,2 occurs predominantly from the neurites. B 1,2 cells were stimulated with three spikes in 0.5 $\mathrm{sec}$ with $0.5 \mathrm{sec}$ interburst intervals for 2 min followed by a $13 \mathrm{~min}$ period of silence. $A$, After the first stimulation period (Control) the primary neurite was cut and the stimulation period repeated (Neurites Severed). This effectively eliminated the stimulation-dependent release of the SCPs $(t=44.48 ; P<0.01)$. Values are mean $\pm \operatorname{SD}(n=3) . B$, Same procedure as in $A$, but the primary neurite was not cut. After the initial release of peptide (Control) the stimulation paradigm was repeated (Neurites Intact). No difference in release was found $(t=0.41$, NS). Values are mean $\pm \operatorname{SD}(n=4)$.

in the number of methionine residues between the SCPs (three residues in the two peptides) and buccalin $A$ (one residue), we calculate that $2.0 \pm 0.2$-fold (mean $\pm \mathrm{SD}, n=3$ ) more SCPs than buccalin $A$ were released. This ratio is similar to the relative rates of peptide synthesis measured in the cell body of B15 in the ganglion (Church and Lloyd, 1991). Thus, B15 neurons in culture release $\mathrm{SCP}_{\mathrm{A}}, \mathrm{SCP}_{\mathrm{B}}$, and buccalin $\mathrm{A}$ in a $\mathrm{Ca}^{2+}$ - and stimulation-dependent manner (Fig. 5). Although we did not investigate the site of this release, the most intense SCP-like immunoreactive structures in culturcd B15 neurons were the varicosities, as we had observed for $\mathrm{B} 1,2$ neurons.

\section{Comparing the effects of tonic versus bursting activity on the release of labeled $S C P S$ from $B 15$}

To examine the role that spike patterning played in the release of peptide from B 15 we used a paradigm in which spike number 


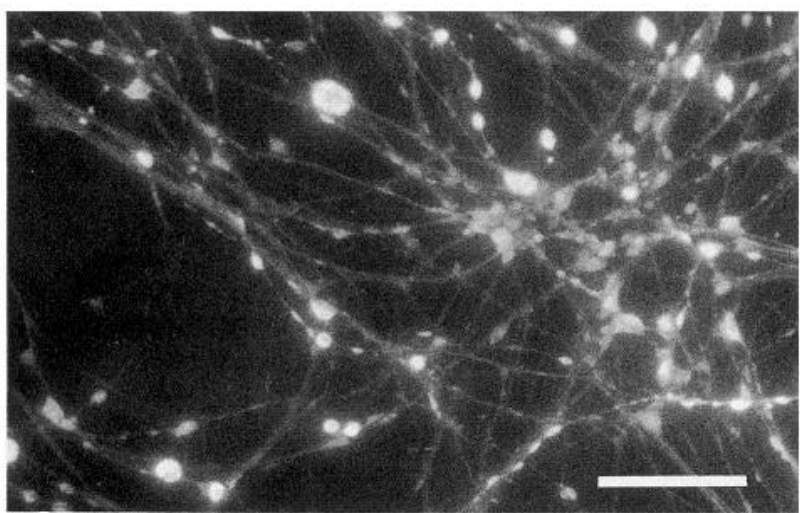

Figure 4. $\mathrm{SCP}_{\mathrm{B}}$-like immunoreactivity in a field of neurites from a cultured $\mathrm{B} 1,2$ neuron: fluorescence micrograph of neurites labeled with a monoclonal antibody to $\mathrm{SCP}_{\mathrm{B}}$ and a secondary antiserum conjugated to fluorescein. Immunoreactivity in the neurites was heavily concentrated in the varicosities. Scale bar, $50 \mu \mathrm{m}$.

was kept constant and spike pattern was varied. The effects of stimulating B15 at a tonic $5 \mathrm{~Hz}$ were compared to stimulating at $50 \mathrm{~Hz}$ for $1 \mathrm{sec}$ with a $9 \mathrm{sec}$ interburst interval. A significant increase in the release of the SCPs was detected using the latter paradigm (6.2-fold; Fig 6A). The $50 \mathrm{~Hz}$ paradigm also released more buccalin A than tonic $5 \mathrm{~Hz}$ firing (7.2-fold; Fig. 6B). Thus, the release of the SCPs and buccalin A is clearly dependent on the pattern of stimulation. This result is in agreement with previous data demonstrating that of these two stimulation paradigms, significant release of the SCPs from B15 neuromuscular synapses only occurs with the $50 \mathrm{~Hz}$ pattern (Whim and Lloyd, 1989, 1990). Thus, in contrast to the release of the SCPs from B1,2 cells, release of the SCPs from B15 appears to be sensitive to the spike pattern.

B15 neurons do not fire at $50 \mathrm{~Hz}$ in the behaving animal and it is possible that the pattern-dependent release of the SCPs observed at high stimulation frequencies is not physiologically relevant. Therefore, the release of the peptides was also examined at lower frequencies. Stimulating B15 tonically at $5 \mathrm{~Hz}$ was compared to stimulation at $\sim 9 \mathrm{~Hz}$ for $4 \mathrm{sec}$ with a $3 \mathrm{sec}$ interburst interval. These two paradigms contained the same overall spike number ( 35 spikes every $7 \mathrm{sec}$ ). Again, more SCPs were released by the bursting paradigm (Fig. 7A). However, there was a decrease in the amount of peptide released by the two $5 \mathrm{~Hz}$ stimulations (compare periods 1 and 3). To examine if this represented a depletion of the pool of releasable peptides, or whether the preceding $9 \mathrm{~Hz}$ stimulation had depressed subsequent release, we stimulated B15 using the tonic $5 \mathrm{~Hz}$ paradigm for all three stimulation periods. An overall decline in release of the SCPs was observed (Fig. $7 B$ ). This phenomenon will tend to underestimate the magnitude of the increase in release caused by the $9 \mathrm{~Hz}$ bursting paradigm. After compensating for this decline, we calculate that the $9 \mathrm{~Hz}$ bursting paradigm released $59 \pm 10 \%$ more labeled SCPs and $70 \pm 33 \%$ more labeled buccalin A than the tonic $5 \mathrm{~Hz}$ paradigm (mean $\pm \mathrm{SD}, n=4$ ). Thus, the release of labeled SCPs and buccalin A from B15 was also sensitive to the stimulation pattern in the physiological range of firing frequencies.

\section{Discussion}

We report here that the regulation of the release of the same peptide transmitters (the SCPs) varies between neurons. Our
A

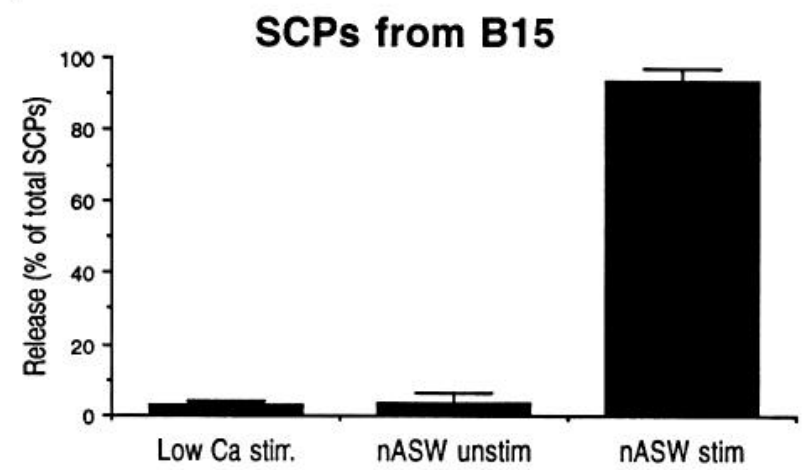

B

\section{Buccalin A from B15}

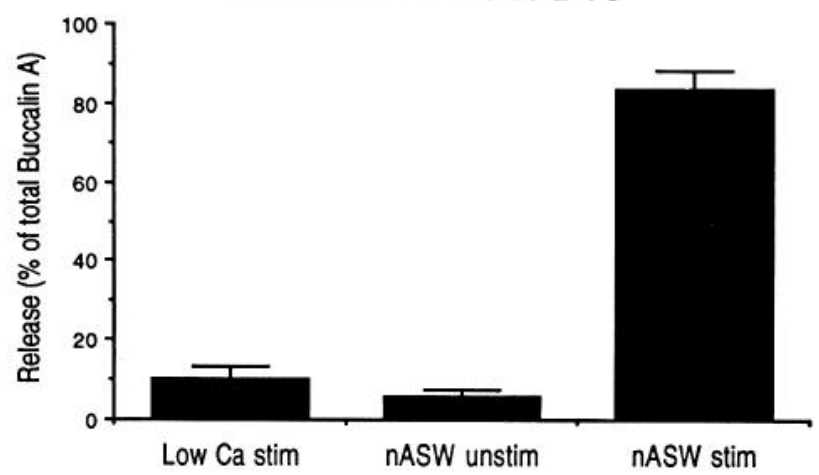

Figure 5. Release of labeled peptide from $\mathrm{B} 15$ cells is $\mathrm{Ca}^{2+}$ and stimulation dependent. Neurons were stimulated at $12 \mathrm{~Hz}$ for $4 \mathrm{sec}$ with 3 sec interburst intervals for $5 \mathrm{~min}$ followed by a $10 \mathrm{~min}$ period of silence. Superfusate was collected from three periods. Authentic SCPs $(A)$ and buccalin $\mathrm{A}(B)$ were released during stimulation in snASW in the third collection period (total counts of $449 \pm 116 \mathrm{cpm}$ and $83 \pm 18 \mathrm{cpm}$, respectively). Values are mean $\pm \mathrm{SD}(n=3)$. Neurons also released two smaller unidentified peaks of radiolabel (total counts of $49 \pm 11 \mathrm{cpm}$ and $40 \pm 8 \mathrm{cpm}$ ).

results suggest that the factors determining the release of the SCPs from motor neurons B 15 and from B1,2 are very different. In spite of testing a variety of stimulation patterns, the release of the SCPs per spike from B1,2 was nearly completely independent of the spike frequency and pattern. In the experiments in which the spike number was kept constant and the spike pattern was varied, even firing B1,2 at an instantaneous frequency of $6 \mathrm{~Hz}$ released only slightly more peptide than tonic stimulation at $1 \mathrm{~Hz}$. Consistent with these observations are the experiments in which B1,2 was fired tonically at a series of frequencies from $1 \mathrm{~Hz}$ to $5 \mathrm{~Hz}$. Again each spike released the same amount of labeled peptides regardless of the stimulation frequency. This linear relationship between spike number and peptide release suggests that each spike fully invaded the sites where neuropeptide release occurred; presumably, these sites were the varicosities. In cultured Retzius cells of a similar size to B1,2, Fromherz and Vetter (1992) have shown that action potentials do indeed fully invade the neuritic tree. Even when the external concentration of calcium was reduced, the release remained linear. It is possible that the appropriate stimulation paradigm was not tested; however, this seems unlikely since we could not stimulate B1,2 cells at frequencies higher than $6 \mathrm{~Hz}$ (either in culture or in the ganglion: Lloyd et al., 1988) and even 
A

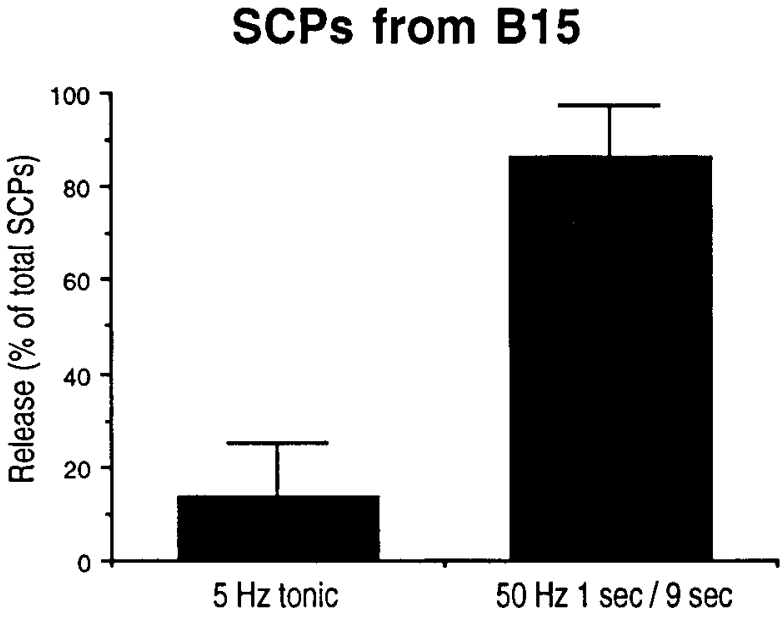

B

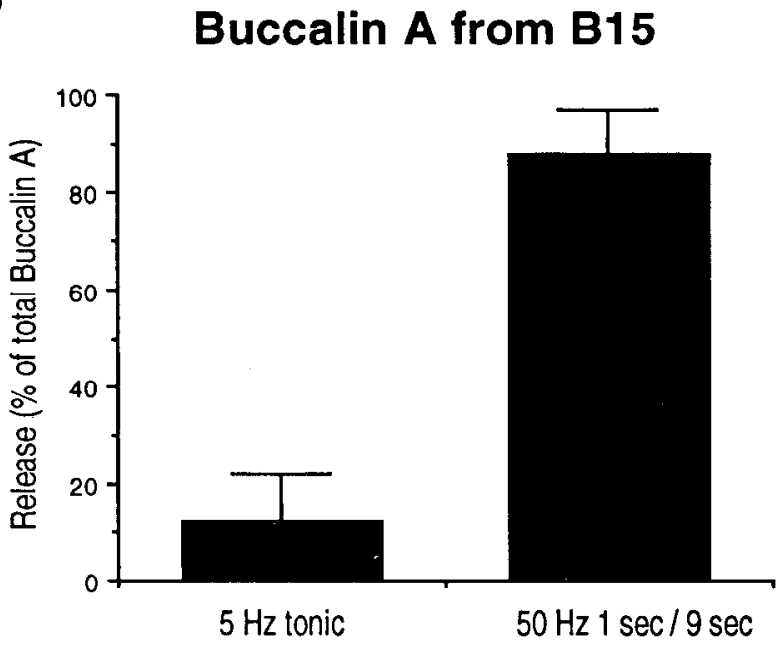

Figure 6. Release of labeled peptide from B15 cells is dependent on the pattern of stimulation. Individual B 15 cells were stimulated in two patterns that contained the same overall number of spikes $(5 \mathrm{~Hz}$ tonic or $50 \mathrm{~Hz}$ for $1 \mathrm{sec}$ with $9 \mathrm{sec}$ interburst intervals) for $5 \mathrm{~min}$ followed by a $10 \mathrm{~min}$ period of hyperpolarization. Experiments were otherwise conducted as described for Figure 1. Stimulation of B15 using the 50 $\mathrm{Hz}$ paradigm was significantly more effective at releasing labeled SCPs $(A, t=7.81, P<0.01)$ and buccalin $\mathrm{A}(B, t=9.84, P<0.01)$ than tonic stimulation at $5 \mathrm{~Hz}$. Values are mean $\pm \mathrm{SD}(n=4)$.

this frequency did not reveal a pattern dependence to the release of the SCPs. In those systems where peptide release per spike was quantitatively analyzed over a broad range of frequencies, the frequency-dependent increase in release per spike was apparent even at frequencies as low as $1 \mathrm{~Hz}$. Indeed, the frequencydependent increase in peptide release was apparent over the range of $1-20 \mathrm{~Hz}$ for $\mathrm{LHRH}$ release from sympathetic neurons (Peng and Horn, 1991) and for oxytocin and vasopressin release from the neurohypophysis (Bondy et al., 1987). Thus, these systems differ significantly from B1,2, which showed essentially no dependence on frequency over the range of 1-6 H7.

Finally, it appears that in semi-intact preparations, stimulation of $\mathrm{B} 1$ at low frequencies is also sufficient to release the SCPs at its target tissue. Intracellular stimulation of B1 at frequencies as low as $1 \mathrm{~Hz}$ evoked contractile activity in the posterior crop that is very similar to that evoked by low concentrations of the SCPs (Lloyd et al., 1988). These observations are consistent
A

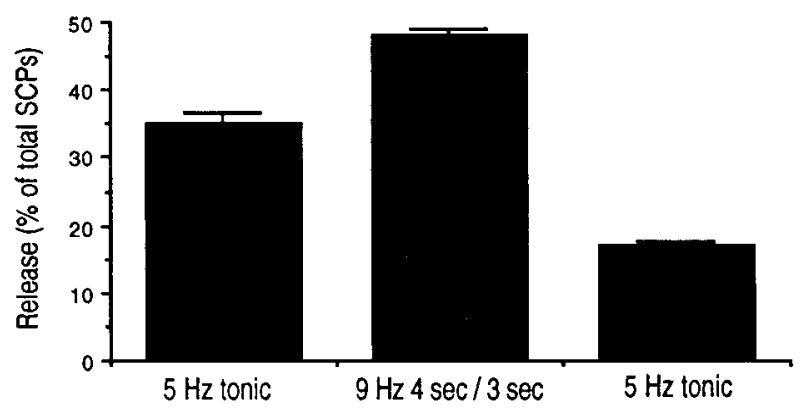

B

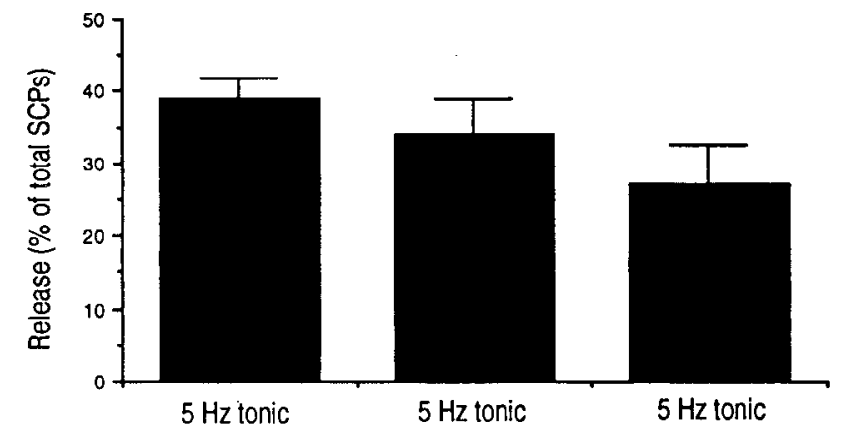

Figure 7. Release of labeled SCPs from B15 cells is dependent on the pattern of stimulation in the physiological range. $A$, Individual $\mathrm{B} 15$ cells were stimulated in two patterns that contained the same overall number of spikes (35 spikes per $7 \mathrm{sec}$, with either $5 \mathrm{~Hz}$ tonic or $4 \mathrm{sec} \sim 9 \mathrm{~Hz}$ bursts with $3 \mathrm{sec}$ interburst intervals) for $5 \mathrm{~min}$ followed by a $10 \mathrm{~min}$ period of hyperpolarization. Stimulation of B15 using the bursting paradigm was significantly more effective at releasing labeled SCPs than tonic stimulation at $5 \mathrm{~Hz}(t=12.9 ; P<0.01)$. Values are mean $\pm \mathrm{SD}$ $(n=4)$. $B$, Individual B15 cells were stimulated as described for $A$ but only the tonic $5 \mathrm{~Hz}$ paradigm was used. A steady decline in the release of labeled SCPs was observed. Values are mean $\pm \mathrm{SD}(n=3)$. The decline in release from the first stimulation period to the third stimulation period was significant $(t=2.9 ; P<0.05)$.

with the present results, which indicate that $1 \mathrm{~Hz}$ stimulation of B1 neurons in culture caused measurable release of the SCPs.

The dependence of release of the SCPs on stimulation pattern that we observed from cultured B 15 neurons showed a marked similarity to that observed in the isolated neuromuscular preparation (Whim and Lloyd, 1989, 1990). Although release was detectable when B15 was fired at a low tonic frequency, it increased dramatically when the same number of spikes was presented in brief high-frequency bursts separated by long interburst intervals. This result was unexpected given that the cells in culture are in the process of regrowing an extensive neuritic arborization and could be considered to be in a developmentally dynamic state. One might expect that factors important in transmitter release, such as the location of membrane calcium channels (Robitaille et al., 1990) would not be typical of thosc of the cell at the mature neuromuscular junction. Certainly, the release of conventional transmitters can vary with the age of the synapse (Role et al., 1987; Evers et al., 1989). Perhaps significant neuropeptide release in culture only occurs from developmentally mature synaptic varicosities. Nevertheless, the present results suggest that the pattern sensitivity of the release of the SCPs is independent of postsynaptic target and arises from factors intrinsic to the neuron. 
In addition to the SCPs, B15 is known to synthesize a variety of neuropeptides, including buccalin A (Cropper et al., 1987, 1988). Using multiple modes of HPLC, we demonstrate that authentic $\mathrm{SCP}_{\mathrm{A}}, \mathrm{SCP}_{\mathrm{B}}$, and buccalin $\mathrm{A}$ were released in a $\mathrm{Ca}^{2+}$ and stimulation-dependent manner. The ratio of recovered SCPS to that of buccalin A was close to that expected from their relative synthesis rates measured in the soma (Church and Lloyd, 1991). Smaller radioactive peaks that initially coeluted with myomodulin A and FMRFamide were determined not to be these peptides when reanalyzed on a second mode of HPLC. The major methionine-containing peaks released in a stimulation-dependent manner from B15 were therefore the SCPs and buccalin $\mathrm{A}$.

While the SCPs and buccalin A are not found in the same precursor molecule (Mahon et al., 1985; Miller et al., 1993), ultrastructural immunocytology has indicated that many of the SCP-immunoreactive dense-core vesicles in the terminals of B 15 in the 15 muscle are also buccalin immunoreactive (Vilim et al., 1990). Stimulation of B15 causes the co-release of the SCP-like and buccalin-like immunoreactivity from these muscles (Vilim et al., 1991). Consistent with these observations we find that the release of buccalin $A$ and the SCPs have a similar pattern dependence. This dependence was most apparent when comparing high-frequency bursts to tonic firing ( $50 \mathrm{~Hz}$ vs $5 \mathrm{~Hz}$ paradigm). A similar difference in release was also found when lower-frequency bursts were compared to tonic activity $(9 \mathrm{~Hz}$ bursts vs $5 \mathrm{~Hz}$ tonic stimulation). Here the bursting paradigm still released $\sim 60 \%$ more peptide than tonic activity. Although we have no accurate measure of what concentration of peptide in the synaptic junction is required to produce a physiological modulation of muscle contractions, an increase in transmitter release of $60 \%$ may have dramatic physiological consequences.

Since $\mathrm{B} 15$ retains a pattern-sensitive release of peptide in culture, it seems likely that the postsynaptic target of B 15 does not play an essential role in generating the pattern specificity of peptide release. This is in contrast to the activity-dependent presynaptic depression of transmitter release at cultured Xenopus neuromuscular synapses, which requires the presence of the postsynaptic muscle fiber (Dan and Poo, 1992).

The pattern sensitivity of the release of the SCPs from B 15 contrasts with the release observed from B1,2 under similar experimental conditions. Although release of the SCPs was observed from $\mathrm{Bl}, 2$ with frequencies as low as $1 \mathrm{~Hz}$, in many experiments firing B15 tonically at $5 \mathrm{~Hz}$ was only just over the threshold for the detectable release of peptide. Even though it was not possible to compare the release of the SCPs from the two cells using the same patterns of stimulation, it appears that the regulation of the release of the same peptides can differ between cells. However, we cannot rule out the possibility that there may be conditions in vivo under which B1,2 fire at frequencies approaching those of $\mathrm{B} 15$. In this range, it is possible that the release of peptide could show pattern dependence. Nevertheless, at frequencies observed to date in the behaving animal, the release of the SCPs from the two types of neurons is clearly sensitive to different aspects of the stimulation paradigm. The SCPs are probably released from $\mathrm{B} 1,2$ by single action potentials, a characteristic commonly associated with conventional transmitters, while their release from B15 probably only occurs during higher-frequency firing. The stimulation requirements for the release of the SCPs from B 15 is thus more typical of the release of peptides in the other systems described above (Cazalis et al., 1985; Bondy et al., 1987; Peng and Horn, 1990).
The mechanisms underlying differences in release characteristics between B1,2 and B15 are presently unknown. Transmitter release is a complex process with the opportunity for modulation existing at many levels. Modulation need not even involve changes in calcium handling (Man-Son-Hing et al., 1989). Possible mechanisms include a frequency-dependent inactivation of potassium currents leading to a broadening of the presynaptic spikc (Aldrich et al., 1979; Jackson et al., 1991), the selective recruitment of novel calcium currents (Artalejo et al., 1991), and the accumulation of presynaptic calcium (Swandulla et al., 1991). Recently, great progress has been made in understanding the roles of both membrane-associated and soluble proteins in mediating the regulated release of transmitters from small synaptic vesicles (De Camilli and Jahn, 1990; Bennett and Scheller, 1993; Sollner et al., 1993). However, progress has been less rapid in the case of the large dense-core vesicles such as those which contain the SCPs, although synaptotagmin, a protein considered crucial for the regulation by calcium of the fusion of small vesicles, has also now been localized to large dense-core vesicles (Walch-Solimena et al., 1993). Thus, differences in the regulation of release of the SCPs from the two cell types might also involve differences in the proteins involved in the regulation of vesicle fusion. Also, the interactions of dense-core vesicles with cytoskeletal elements, which is thought to be a crucial regulatory step in their exocytosis (Trifaro' et al., 1992), may be controlled differently by the two cell types. We are currently attempting to resolve which of these mechanisms underlies the differences in release of the SCPs from these neurons. Finally, the release of other transmitters from B15 (such as ACh or buccalin A) may also have presynaptic roles in regulating the release of the peplides.

These results indicate that cultured Aplysia neurons are a useful model system with which to investigate directly the release of peptide transmitters. We report here that as was previously demonstrated in isolated neuromuscular preparations, the release of peptide from B15 in culture is sensitive to the stimulation pattern (Whim and Lloyd, 1989, 1990). However, peptide release is not always regulated in this manner because, as the experiments with B1,2 indicate, peptides can be released with little dependence on frequency or pattern.

\section{References}

Aldrich RW, Getting PA, Thompson SH (1979) Mechanism of frequency-dependent broadening of molluscan neurone soma spikes. J Physiol (Lond) 291:531-544.

Artalejo CR, Dahmer MK, Perlman RL, Fox AP (1991) Facilitation of $\mathrm{Ca}^{2+}$ current in bovine chromaffin cells is due to recruitment of a second type of whole-cell current with novel properties. J Physiol (Lond) 432:681-707.

Bartfai T, Iverfeldt K, Fisone G, Serfozo P (1988) Regulation of the release of coexisting transmitters. Annu Rev Pharmacol Toxicol 28: 285-310.

Bennett MK, Scheller RH (1993) The molecular machinery for secretion is conserved from yeast to neurons. Proc Natl Acad Sci USA 90: $2559-2563$.

Bondy CA, Gainer II, Russell JT (1987) Effects of stimulus frequency and potassium channel blockade on the secretion of vasopressin and oxytocin from the neurohypophysis. Neuroendocrinology 46:258-267.

Cazalis M, Dayanthi G, Nordmann JJ (1985) The role of patterned burst and interburst interval on the excitation-coupling mechanism in the isolated rat neural lobe. J Physiol (Lond) 369:45-60.

Church PJ, Lloyd PE (1991) Expression of diverse neuropeptide cotransmitters by identified motor neurons in Aplysia. J Neurosci 11: 618-625.

Church PJ, Whim MD, Lloyd PE (1993) Modulation of neuromuscular transmission by conventional and peptide transmitters released 
from excitatory and inhibitory motor neurons in Aplysia J Neurosci 13:2790-2800.

Cohen JL, Weiss KR, Kupfermann I (1978) Motor control of buccal muscles in Aplysia. J Neurophysiol 41:157-180

Cropper EC, Lloyd PE, Reed W, Tenenbaum R, Kupfermann I, Weiss KR (1987) Multiple neuropeptides in cholinergic motor neurons of Aplysia: evidence for modulation intrinsic to the motor circuit. Proc Natl Acad Sci USA 84:3486-3490.

Cropper EC, Miller MW, Tenenbaum R, Kolks MA, Kupfermann I, Weiss KR (1988) Structure and action of buccalin: a modulatory neuropeptide localized to an identified small cardioactive peptidecontaining cholinergic motor neuron of Aplysia californica. Proc Natl Acad Sci US 85:6177-6181.

Cropper EC, Kupfermann I, Weiss KR (1990a) Differential firing patterns of the peptide-containing cholinergic motor neurons $\mathrm{B} 15$ and B16 during feeding in Aplysia. Brain Res 522:176-179.

Cropper EC, Price D, Tenenbaum R, Kupfermann I, Weiss KR (1990b) Release of peptide cotransmitters from a cholinergic neuron under physiological conditions. Proc Natl Acad Sci USA 87:933-937.

Dan Y, Poo M-m (1992) Hebbian depression of isolated neuromuscular synapses in vitro. Science 256:1570-1573.

De Camilli P, Jahn R (1990) Pathways to regulated exocytosis in neurons. Annu Rev Physiol 52:625-645.

Dutton D, Dyball REJ (1979) Phasic firing enhances vasopressin release from the rat neurohypophysis. J Physiol (Lond) 290:433-440.

Evers J, Laser M, Sun Y-A, Poo M-M (1989) Studies of nerve-muscle interactions in Xenopus cell culture: analysis of early synaptic currents. J Neurosci 9:1523-1539.

Fromherz P, Vetter T (1992) Cable properties of arborized Retzius cells of the leech in culture as probed by a voltage-sensitive dye. Proc Natl Acad Sci USA 89:2041-2045.

Gardner D (1971) Bilateral symmetry and interneuronal organization in the buccal ganglia of Aplysia. Science 173:550-553.

Hall JD, Lloyd PE (1991) Release of pedal peptide from Aplysia neurons in primary culture. J Neurobiol 22:583-589.

Haydon PG (1988) The formation of chemical synapses between cellcultured neuronal somata. J Neurosci 8:1032-1038.

Jackson MB, Konnerth A, Augustine GJ (1991) Action potential broadening and frequency-dependent facilitation of calcium signals in pituitary nerve terminals. Proc Natl Acad Sci USA 88:380-384.

Lloyd PE, Schacher S, Kupfermann I, Weiss KR (1986) Calciumdependent release of neuropeptides during intracellular stimulation of single identified Aplysia neurons in culture. Proc Natl Acad Sci USA 83:9794-9798.

Lloyd PE, Kupfermann I, Weiss KR (1987) Sequence of small cardinactive peptide $\mathrm{A}$ : a second member of a class of neuropeptides in Aplysia. Peptides 8:179-184.

Lloyd PE, Kupfermann I, Weiss KR (1988) Central peptidergic neurons regulate gut motility in Aplysia. J Neurophysiol 59:1613-1626.

Mahon AC, Lloyd PE, Weiss KR, Kupfermann I, Scheller RH (1985) The small cardioactive peptides A and B of Aplysia are derived from a common precursor molecule. Proc Natl Acad Sci US 82:3925-3929.

Man-Son-Hing H, Zoran MJ, Lukowiak K, Haydon PG (1989) A modulator of synaptic transmission acts on the secretory apparatus as well as on ion channels. Nature 341:237-239.

Masinovsky B, Kempf SC, Callaway JC, Willows AOD (1988) Monoclonal antibodies to the molluscan small cardioactive peptide $\mathbf{S C P}_{\mathrm{B}}$ : immunolabeling of neurons in diverse invertebrates. J Comp Neurol 273:500-512.

Miller MW, Beushausen S, Cropper FC. Fisinger K. Stamm S, Vilim
FS, Vitek A, Zajc A, Kupfermann I, Brosius J, Weiss KR (1993) The buccalin-related neuropeptides: isolation and characterization of an Aplysia cDNA clone encoding a family of peptide transmitters. J Neurosci 13:3346-3357.

Morris HR, Panico M, Karplus A, Lloyd PE, Riniker B (1982) Elucidation by FAB-MS of the structure of a new cardioactive peptide from Aplysia. Nature 300:643-645.

Peng Y, Horn JP (1991) Continuous repetitive stimuli are more effective than bursts for evoking LHRH release in bullfrog sympathetic ganglia. J Neurosci 11:85-95.

Reed, W, Weiss KR, Lloyd PE, Kupfermann I, Chen M, Bailey CH (1988) Association of neuroactive peptides with the protein secretory pathway of identified neurons in Aplysia californica: immunolocalization of SCPA and SCPB to the contents of dense-core vesicles and the trans face of the Golgi apparatus. J Comp Neurol 272:358-369.

Robitaille R, Adler EM, Charlton MP (1990) Strategic location of calcium channels at transmitter release sites of frog neuromuscular synapses. Neuron 5:773-779.

Role LW, Roufa DG, Fischbach GD (1987) The distribution of acetylcholine receptor clusters and sites of transmitter release along chick ciliary ganglion neurite-myotube contacts in culture. J Cell Biol 104: $371-379$.

Sollner T, Whiteheart SW, Brunner M, Erdjument-Bromage H, Geromanos M, Tempst P, Rothman JE (1993) SNAP receptors implicated in vesicle targeting and fusion. Nature 362:318-324.

Susswein A, Weiss KR, Kupfermann I (1978) The effects of food arousal on the latency of biting in Aplysia. J Comp Physiol 123:3141.

Swandulla D, Hans M, Zipser K, Augustine GJ (1991) Role of residual calcium in synaptic depression and posttetanic potentiation: fast and slow calcium signaling in nerve terminals. Neuron 7:915-926.

Trifaro' J-M, Vitale ML, Del Castillo AR (1992) Cytoskeleton and molecular mechanisms in neurotransmitter release by neurosecretory cells. Eur J Pharmacol Mol Pharmacol 225:83-104.

Vilim FS, Kupfermann I, Weiss KR (1990) Ultrastructural localization of SCP and buccalin-like immunoreactivity in the accessory radula closer muscle of Aplysia. Soc Neurosci Abstr 16:306.

Vilim FS, Price DA, Lesser W, Kupfermann I, Weiss KR (1991) Direct measurement of peptide co-transmitter release following intracellular stimulation of a single identified motor neuron in Aplysia. Soc Neurosci Abstr 17:1305

Walch-Solimena C, Takei K, Marek KL, Midyett K, Sudhof TC, De Camilli P, Jahn R (1993) Synaptotagmin: a membrane constituent of neuropeptide-containing large dense core vesicles. J Neurosci 13: 3895-3903.

Whim MD, Lloyd PE (1989) Frequency-dependent release of peptide cotransmitters from identified cholinergic motor neurons in Aplysia. Proc Natl Acad Sci US 86:9034-9038.

Whim MD, Lloyd PE (1990) Ncuropeptidc cotransmitters released from an identified cholinergic motor neuron modulate neuromuscular efficacy in Aplysia. J Neurosci 10:3313-3322

Whim MD, Lloyd PE (1992) Modulation of peptide release from single identified Aplysia neurons in culture. J Neurosci 12:3545-3553.

Whim MD, Church PJ, Lloyd PE (1993) Functional roles of peptide cotransmitters at neuromuscular synapses in Aplysia. Mol Neurobiol $7: 335-347$

Willard A (1990) A vasoactive intestinal peptide-like cotransmitter at cholinergic synapses between rat myenteric neurons in cell culture. $\mathbf{J}$ Neurosci 10:1025-1034. 